Note: this is a peer-reviewed and approved draft of the journal article:

Dickinson, A.S., (2016) "Activity Intensity, Assistive Devices and Joint Replacement Influence Predicted Remodelling in the Proximal Femur". Biomechanics and Modeling in Mechanobiology, 15(1) 181-194, DOI: 10.1007/s10237-015-0678-9

The final publication is available from the publisher, Springer, at link.springer.com.

Special Issue Paper: "Bone and Cartilage Mechanobiology across the scales", edited by A/P Peter Pivonka, Dr Justin Fernandez and Prof Peter Hunter

\title{
Activity Intensity, Assistive Devices and Joint Replacement Influence Predicted Remodelling in the Proximal Femur
}

\section{A S Dickinson MEng PhD ${ }^{1^{*}}$}

*Contact Details of Corresponding Author:

Bioengineering Science Research Group,

Mailpoint M7,

University of Southampton,

Highfield,

Southampton,

SO17 1BJ,

United Kingdom

Email: alex.dickinson@soton.ac.uk

Telephone: 00442380595394

Fax: 00442380593016

The majority of the work in this manuscript was presented at the 11th World Congress of Computational Mechanics (July, 2014, Barcelona, Spain), in the "Bone and Cartilage Mechanobiology: experimental and computational assessment across the scales" symposium. 


\section{Abstract}

Bone morphology and density changes are commonly observed following joint replacement, and may contribute to the risks of implant loosening and periprosthetic fracture, and reduce the available bone stock for revision surgery. This study was presented in the "Bone and Cartilage Mechanobiology across the scales" WCCM symposium to review the development of remodelling prediction methods and to demonstrate simulation of adaptive bone remodelling around hip replacement femoral components, incorporating intrinsic (prosthesis) and extrinsic (activity and loading) factors.

An iterative bone remodelling process was applied to finite element models of a femur implanted with a cementless THR (total hip replacement) and a hip resurfacing implant. Previously developed for a cemented THR implant, this modified process enabled the influence of pre- to postoperative changes in patient activity and joint loading to be evaluated. A control algorithm used identical pre- and postoperative conditions, and the predicted extents and temporal trends of remodelling were measured by generating virtual $x$-rays and DXA scans.

The modified process improved qualitative and quantitative remodelling predictions for both the cementless THR and resurfacing implants, but demonstrated the sensitivity to DXA scan region definition and appropriate implant-bone position and sizing. Predicted remodelling in the intact femur in response to changed activity and loading demonstrated that in this simplified model, although the influence of the extrinsic effects were important, the mechanics of implantation were dominant. This study supports the application of predictive bone remodelling as one element in the range of physical and computational studies, which should be conducted in the pre-clinical evaluation of new prostheses.

\section{Keywords}

predicted bone remodelling; total hip replacement; hip resurfacing; FE analysis; 


\section{Introduction}

Bone morphology and density changes are commonly observed following joint replacement. These changes are associated in part with adaptive remodelling processes, in response to changed biomechanical conditions in the periprosthetic bone, and an attempt to recover homeostasis. Bone's functional adaptation was originally identified as a response to extrinsic drivers, such as the activity of an individual (Wolff 1892). Remodelling is also understood to result from the intrinsic effects of orthopaedic surgery, whereby the host aims to repair traumatic or surgical damage from implantation, and to respond to changes in the path of loading which result from the substantial differential stiffness between an implant and surrounding tissues.

In total hip replacement (THR), implantation of the proximal femur with a stiff metal femoral stem to support an artificial bearing is recognised to produce proximal load bypass and distal load increase (Bobyn et al 1992). This corresponds with loss of proximal trabecular bone mineral density (BMD) and cortical thickness (Brodner et al 2004; Chandran et al 2012; Stucinskas et al 2012; Jayasuriya et al 2013), distal cortical thickening (Abadie et al 2010), and in cementless implants the formation of trabecular pedestal features (Slack et al 2006). In resurfacing hip replacement $(\mathrm{RHR})$, replacement of the femoral articular cartilage and a layer of supporting bone with a stiff metal shell leads to cancellous bone resorption inside the femoral head and a narrowing of the femoral neck at its junction with the head. Again this has been associated with redirection of joint loading down the implant's metaphyseal stem into the medial neck cortex, bypassing the proximal tissue. This is evidenced by the formation of trabecular pedestal signs around the stem and densification of the medial/distal femoral neck trabecular structures (Amstutz, Beaulé et al 2004; Pollard et al 2006).

In both cases, resorption may also result from osteolytic reactions to debris released by the implant, or from the vascular insult of the surgery, but the high incidence of these changes indicates that mechanoregulatory effects are dominant. Dual energy $x$-ray absorptiometry (DXA) is used clinically to quantify changes in periprosthetic bone mineral density (BMD) (Cohen and Rushton 1995), and has shown that remodelling frequently stabilises, indicating that adaptation is sufficient to achieve a return to homeostasis. However, bone remodelling evidence is seen more commonly in poorly performing implants (Pollard et al 2006), and it has been suggested that extensive bone remodelling may increase the risk of periprosthetic fracture, either under traumatic loads or in association with agerelated bone loss (Hing et al 2007). Where substantial bone remodelling results from distal load redistribution along a prosthesis stem, the bending stress in the implant will rise, potentially increasing the risk of prosthesis fracture. Finally, widespread periprosthetic resorption reduces the available bone stock in any subsequent revision surgery, increasing the difficulty of achieving fixation and an acceptable outcome.

The ability to predict periprosthetic bone remodelling is of value in orthopaedic implant development. Whilst the performance of all new medical devices should be verified with care in controlled clinical conditions, computational biomechanical predictions may help to inform the development process, and to screen candidate designs prior to clinical evaluation. The extent of adaptive changes should be predicted and compared to current clinically successful prostheses, and the risk of mechanical failure in both the implant and the supporting bone can be evaluated, both immediately postoperatively and after a period of predicted remodelling. Clearly, the validity of such a predictive tool must be evaluated as broadly as possible before it can be used as part of the pre-clinical analysis of new prosthesis concepts.

Computational prediction of periprosthetic bone remodelling is established, based on a foundation of phenomenological and microstructural approaches. The phenomenological approach stems from work in the 1980s in Nijmegen (Huiskes et al 1987; Weinans et al 1991; van Rietbergen et al 1993; Weinans et al 1993). Finite element (FE) analysis was employed to predict the heterogeneity present in trabecular bone on a continuum level. A comparison of the local strain energy density (SED) distribution in an implanted bone model with reference SED levels in an intact control model was used to predict changes in cortical shape and trabecular density. A mechanostat principle was applied, based upon the strain history stimulus required to produce a bone volume change (Carter 1984), and 
implemented using Euler forward integration to calculate iterative changes in the thickness of cortex elements (external remodelling), or the heterogeneous density- and hence the Young's modulus- of trabecular elements (internal remodelling). This method has been applied to femoral implants in THR (Kerner et al 1999; Turner et al 2005), RHR (Gupta et al 2006; Pal et al 2009; Rothstock et al 2011; Dickinson et al 2012; Perez et al 2014), to acetabular cups (Ghosh et al 2013), and in other joints (van Lenthe et al 1997). Advanced approaches have combined strain adaptive bone remodelling with other associated mechanobiological processes, including cementless implant ingrowth (Tarala et al 2011) and periprosthetic defect healing (Dickinson et al 2012).

Other researchers have employed different mechanical stimuli, including stress non-uniformity (Adachi et al 1997) and continuum damage mechanics, where the maintenance of a combination of homeostatic damage and strain levels is used as the remodelling stimulus (Scannell and Prendergast 2009). Furthermore, internal remodelling has been simulated by damage repair whilst accounting at the continuum level for microstructural directionality adaptations, by assigning material anisotropy and predicting its changes in response to local stress tensor deviations (Doblaré and Garcia 2001). This was demonstrated first with THR and applied more recently to RHR (Caouette et al 2012).

The main alternative, microstructural, approach employs shape optimisation methods to minimise the strain energy of the bone structure by redistributing material in order to maximise the structural stiffness. This was applied at first for external remodelling (Doblaré and Garcia 2001; Garcia et al 2001) and more recently has been used to attempt to reproduce realistic trabecular structures through micro-FE and design space optimisation (DSO), first in two dimensions (Jang and Kim 2010) and then in 3D (Boyle and Yong Kim 2011).

The continuum strain-adaptive mechanostat principle is the most widely used. In current implementations, internal and external remodelling is represented by adjusting each element's density ' $\rho$ ' over a time increment ' $\Delta t^{\prime}$, according to changes in its SED level (' $S$ ') in comparison to its reference SED level from the intact bone model ' $S_{\text {ref }}$ ':

if:

$$
\rho_{i+1}=\rho_{i}+a(\rho) \tau\left[S-(1 \pm s) S_{r e f}\right] \Delta t
$$

$$
S \leq(1-s) S_{\text {ref }} \text { or } S \geq(1+s) S_{\text {ref }}
$$

or:

if:

$$
\rho_{i+1}=\rho_{i}
$$

$$
(1-s) S_{r e f}<S<(1+s) S_{r e f}
$$

This includes a function ' $a(\rho)$ ' which adjusts the remodelling rate according to the porous free surface available for osteoclast and osteoblast activity (Martin 1984), and prevents remodelling outside the range of 0 and $100 \%$ porosity. Importantly, the model employs two parameters which are used to tune the remodelling predictions to clinical data: a rate constant ' $\tau$ ', and a threshold remodelling stimulus ' $s$ '. The time constant is adjusted retrospectively, to translate the model time in computer cycles into months, by identifying the point at which remodelling adaptation is complete and setting this equal to clinical measurements of time to achieve homeostasis. A threshold remodelling stimulus must also be defined, and this determines the extent of density adaptation. A value of $75 \%$ is commonly used for elderly THR patients, following empirical fitting of remodelling predictions to radiographic data (Weinans et al 1991), and some researchers use a lower threshold stimulus of 60-65\% for younger patients (Turner et al 2005) or those receiving RHR implants (Dickinson et al 2010), to represent higher metabolism or sensitivity to osteocyte signals. The size of the time increment ' $\Delta t$ ' is calculated at each iteration, according to a set limit to the greatest permitted elemental density change which aids numerical convergence.

Considering total hip replacement, this approach produces results which agree qualitatively with the main clinical radiographic observations including proximal bone resorption and distal densification. In the past, predictive studies evaluated correlations between pre- to postoperative changes in periprosthetic stress and strain, and zones of clinically observed BMD change (Skinner et al 1994), which is a test of the link between the postoperative remodelling stimulus 
and the final remodelled state. Currently, virtual x-rays and DXA scans are performed upon adaptive FE models to extract qualitative and quantitative bone structure change predictions, which are compared to equivalent clinical measurements. In THR, these measurements and predictions are generally made in 7 defined 'Gruen zones' (Gruen et al 1979) around the implant, and in RHR, a variety of zones around the implant's metaphyseal stem are used (Kishida et al 2004). Commonly, the empirical fit of the mechanostat parameters for remodelling rate and threshold stimulus is performed using the medial calcar Gruen zone 7, which is the most reactive zone.

For some time there was limited quantitative clinical evidence of periprosthetic BMD changes (Cohen and Rushton 1995; Wilkinson et al 2001), and only more recently has the availability of DXA data become sufficient to enable more thorough spatiotemporal assessment of the validity of these predictions across the full periprosthetic region: for cemented THR (Jayasuriya et al 2013), cementless THR (Leichtle et al 2005; Kim et al 2007; Penny et al 2012), and for hip resurfacing (Kishida et al 2004; Lian et al 2008; Häkkinen et al 2011; Penny et al 2012; Huang et al 2013; Gerhardt et al 2014). This data demonstrated that past modelling studies have not reproduced clinically representative temporal trends of remodelling. The majority of models predict exponential BMD loss or increase to a homeostatic level in all Gruen zones, in agreement with clinical trends in the most reactive proximal Gruen zone 7 . The cited clinical studies showed that BMD losses are often faster stabilising in the mid-stem zones ( 2 and 6 ), and that loss-recovery trends occur in more distal and lateral zones (3-5 and 1). The loss-recovery BMD change trend is also common in the bone supporting hip resurfacing implants, and is recorded distant from the implant (Lian et al 2008) and to some extent in the contralateral limb (Häkkinen et al 2011), suggesting that there is a contribution of extrinsic effects.

Joint loading and activity are known to stimulate bone remodelling, and are likely to follow a similar trend during the recovery and rehabilitation period. The pain relief achieved in the first 6 postoperative months by successful arthroplasty (Stulberg et al 2010) allows an increase in activity, by between 10 and 30\% (de Groot et al 2008; Daniel et al 2009; Kuhn et al 2013) compared to preoperative levels. Preoperative joint loading is also likely to be reduced by use of walking aids, by 20-40\% (Brand and Crowninshield 1980; Ajemian et al 2004). Postoperative joint loading may also be reduced as a result of medialisation of the joint centre location by around 10\% (Johnston et al 1979; Bonnin et al 2012). Activity and load scaling factors were devised to augment the established strain adaptive remodelling process, and were demonstrated to improve the predicted temporal trends and homeostatic levels of periprosthetic BMD change in response to cemented total hip replacement (Dickinson 2014). Recognising that this approach is based on a phenomenological model and literature-based adjustment factors, the present study set out to perform a further objective evaluation of its performance, using cementless total hip replacement and hip resurfacing implant case studies. 


\section{Methodology}

\section{Computational Modelling Process}

FEA models were produced and used to predict the longitudinal periprosthetic BMD changes in response to two clinically successful joint replacement implant femoral components: a cementless THR and a cemented/hybrid RHR. The methodology of the present study was based closely upon that presented for the Charnley cemented THR in preceding work (Dickinson 2014), and is summarised below.

An FE model of the proximal two-thirds of a femur was produced from the CT scan of a 63-year old male, typical total or hip resurfacing patient, of height $1.77 \mathrm{~m}$ and mass $85 \mathrm{~kg}$. The external cortex surface was identified by CT-volume segmentation (Amira, Mercury Computer Systems Inc, USA), and converted into a solid NURBS CAD model upon which virtual surgery was performed (SolidWorks, SolidWorks Corp, USA). For the THR model, cutting tools were generated from Furlong HAC implant geometry, size 12, provided by JRI Orthopaedics Ltd., UK, representing the stem geometry and femoral neck osteotomy plane, and used to partition the bone model.

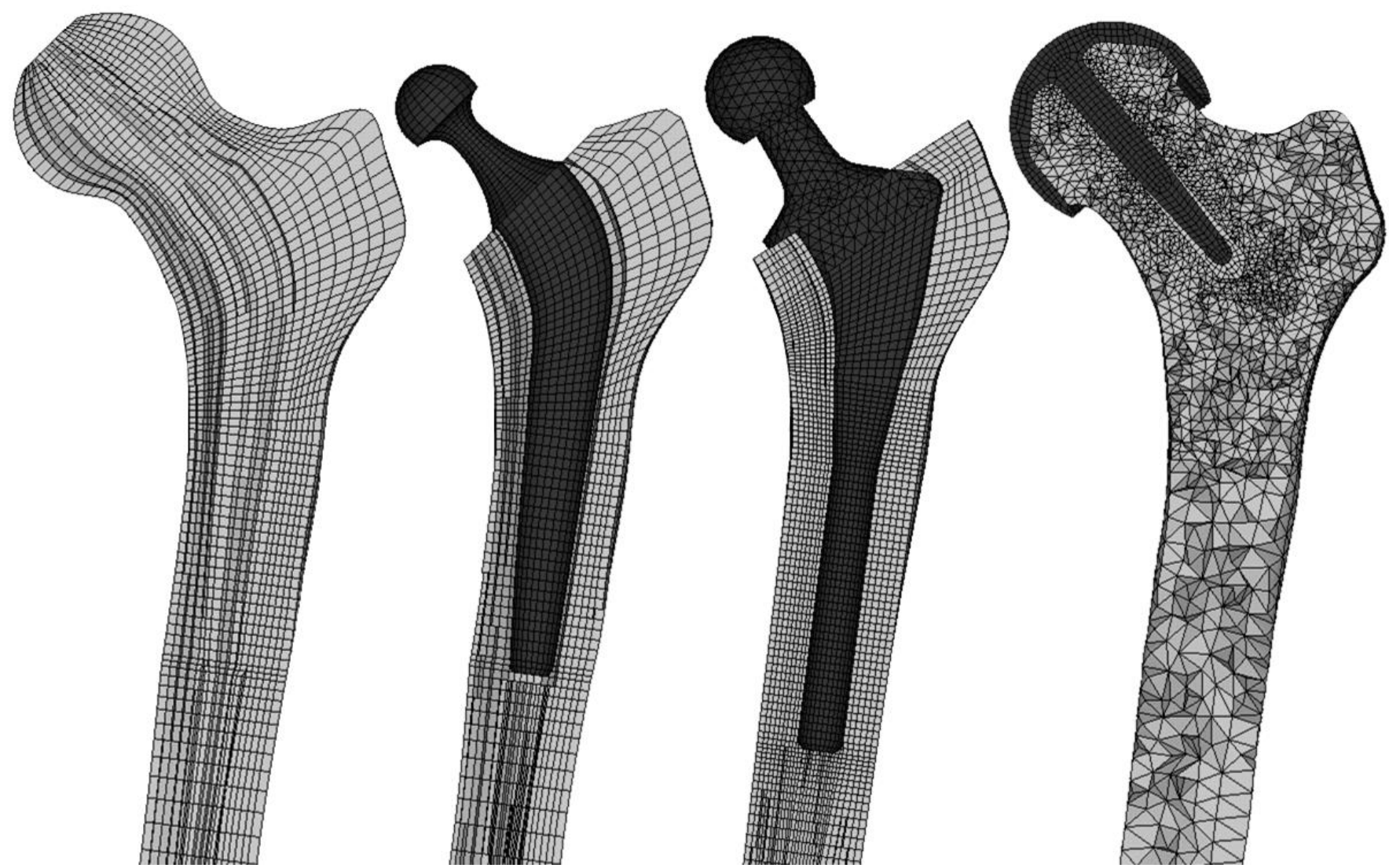

Figure 1: Sections of FE Meshes for (left to right) intact, and implanted models: cemented THR, cementless THR and RHR

The excised femoral head and neck regions were retained, so that the reference stimulus level could be calculated for the remodelling bone elements using an intact femur model. The partitioned femur and implant models were loaded into an FEA environment (ANSYS 14.5, ANSYS Inc., USA), for meshing and analysis. A second order finite element mesh comprising 61859 solid elements and 249529 nodes (Figure 1) was selected by mesh convergence analysis. Mapped hexahedral elements were used for the remodelling bone regions, and tetrahedral elements were used for practicality, in the proximal region of the implant and the excised femoral head and neck. A contact pair was defined between the stem and supporting bone, and assigned a coefficient of static friction of 0.5 (Rancourt et al 1990).

The implant stem was assigned the linear elastic material properties of Ti-6Al-4V (ASTM F136-08): Young's Modulus $E=114 \mathrm{GPa}$, Poisson's ratio $v=0.34$. The apparent density of each bone element was extracted from the CT data using Bonemat (Rizzoli Institute, Bologna), assuming a density of $1.73 \mathrm{~g} / \mathrm{cc}$ for $100 \%$ dense diaphyseal cortical bone, and a density of $0 \mathrm{~g} / \mathrm{cc}$ in the medullary canal. Density was used to calculate Young's Modulus according to the relationship 
$E=6850 \rho^{1.49}$ (Morgan et al 2003). Partial volume effects of CT scan segmentation and material property extraction were removed by mapping the Young's Modulus of each surface element to that of the nearest neighbouring internal element. A quasi-static load case representing the heelstrike instant in gait was applied (Heller et al 2005), for joint contact, abductor, tensor fascia latae and vastus lateralis forces.

For the resurfaced femur scenario, a previously reported FE model featuring the Birmingham Hip Resurfacing (Smith\&Nephew Inc., USA) was employed (Dickinson et al 2010; Dickinson et al 2012). This was generated in the same way, but employed a verified second order tetrahedral mesh of 84613 elements and 143325 nodes (Figure 1). The implant was assigned material properties representing ASTM-F75 Cobalt Chromium alloy, and its shell was supported by a $2 \mathrm{~mm}$ thick layer of PMMA bone cement, with all interfaces bonded except for the stem-bone interface which employed contact and a static coefficient of friction of 0.3 .

\section{Study Design}

Periprosthetic bone remodelling was predicted over the first 60 postoperative months for both models, employing the strain-adaptive mechanostat principle. In the THR model, bone remodelling alone was considered. In the RHR model, a combined periprosthetic defect healing - bone remodelling process was used (Dickinson et al 2012), which accounted for the diffusion of mesenchymal stem cells into the surgical defect created to accommodate the implant metaphyseal stem, and their subsequent differentiation and maturation in response to mechanobiological stimuli (Claes and Heigele 1999).

\begin{tabular}{|c|c|c|c|c|c|c|c|}
\hline \multirow{2}{*}{ Case } & \multirow{2}{*}{ Description } & \multirow{2}{*}{ s/\% } & \multicolumn{2}{|c|}{ Initial } & \multirow{2}{*}{$\begin{array}{c}\text { Transient } \\
t_{\text {rehab }} / \text { mo. }\end{array}$} & \multicolumn{2}{|c|}{ Final } \\
\hline & & & $F_{\text {act }, 0}$ & $F_{\text {load }, 0}$ & & $F_{\text {act,1 }}$ & $F_{\text {load,1 }}$ \\
\hline THR 1 & Control & 75 & 1.00 & 1.00 & - & 1.00 & 1.00 \\
\hline THR 2 & $\begin{array}{c}\text { Weak Recovery: } \\
\text { Double Preop Cane Use, } \\
\text { Single Postop Cane Use, } \\
\text { Low Activity Increase }\end{array}$ & 75 & 1.00 & 0.60 & 1.5 & 1.10 & $\begin{array}{c}0.92 \\
x \\
0.78\end{array}$ \\
\hline THR 3 & $\begin{array}{l}\text { Intermediate Recovery: } \\
\text { Single Preop Cane Use, } \\
\text { No Postop Cane Use, } \\
\text { Low Activity Increase }\end{array}$ & 75 & 1.00 & 0.78 & 1.5 & 1.10 & 0.92 \\
\hline THR 4 & $\begin{array}{l}\text { Strong Recovery: } \\
\text { Single Preop Cane Use, } \\
\text { No Postop Cane Use, } \\
\text { High Activity Increase }\end{array}$ & 75 & 1.00 & 0.78 & 1.5 & 1.30 & 0.92 \\
\hline RHR 1 & & 75 & 1.00 & 1.00 & - & 1.00 & 1.00 \\
\hline RHR 2 & & 62.5 & 1.00 & 1.00 & - & 1.00 & 1.00 \\
\hline RHR 3 & $\begin{array}{l}\text { Strong Recovery: } \\
\text { Single Preop Cane Use, } \\
\text { No Postop Cane Use, } \\
\text { High Activity Increase }\end{array}$ & 75 & 1.00 & 0.78 & 1.5 & 1.30 & 0.92 \\
\hline
\end{tabular}

Table 1: Modelled loading and activity factor cases

Time-varying activity and loading factors $\left(\mathrm{F}_{\text {act }}\right.$ and $\left.\mathrm{F}_{\text {load }}\right)$ were applied to the remodelling stimuli to account for the described effects of walking aid use preoperatively and during rehabilitation, and gradual recovery from surgery to a higher level activity than the symptomatic preoperative reference case (Dickinson 2014). These scaling factors were applied directly to the remodelling stimulus signal, rather than to the FE model loading; the validity of this method holds while the FE model maintains approximately linear load-strain behaviour. The analysis matrix is given in Table 1. Both remodelling simulations were run first assuming identical preoperative and postoperative activity and loading, for control. The RHR model was analysed with two control algorithm cases, representing low and high sensitivity to 
remodelling stimulus ( $s=75 \%$ and $62.5 \%$ ). Then, three activity and loading profiles were compared to the control case for the THR, representing weak, intermediate and strong recovery. Only the strong recovery profile was used for the RHR model, representing the more likely outcome for the young hip resurfacing candidate patient.

\section{Modelling Outputs}

The models were interrogated using virtual $x$-rays, and virtual DXA scans for qualitative and quantitative corroboration with literature data, respectively. Virtual x-rays were generated by overlaying a quadrilateral meshed plane upon the model, each element representing single $x$-ray or pixel in the generated image. The linear attenuation of each solid model element was added to each $\mathrm{x}$-ray pixel it would project onto, and the fractional transmitted intensity ' $I / I_{0}{ }^{\prime}$ was calculated for each pixel by summing its attenuation (Turner et al 2005; Dickinson et al 2012). The transmitted intensity was then plotted on the pixels by greyscale.

Virtual DXA scans were generated according to clinical protocols (Wilkinson et al 2001). Seven periprosthetic zones were used in the THR model (Gruen et al 1979), and 6 zones were used in the RHR model (Kishida et al 2004), three in the medial and three in the lateral femoral neck (Figure 2). The areal sum of BMD of the solid model elements underlying each zone was extracted after each remodelling iteration, and expressed as a percentage of the zone's immediately postoperative value.

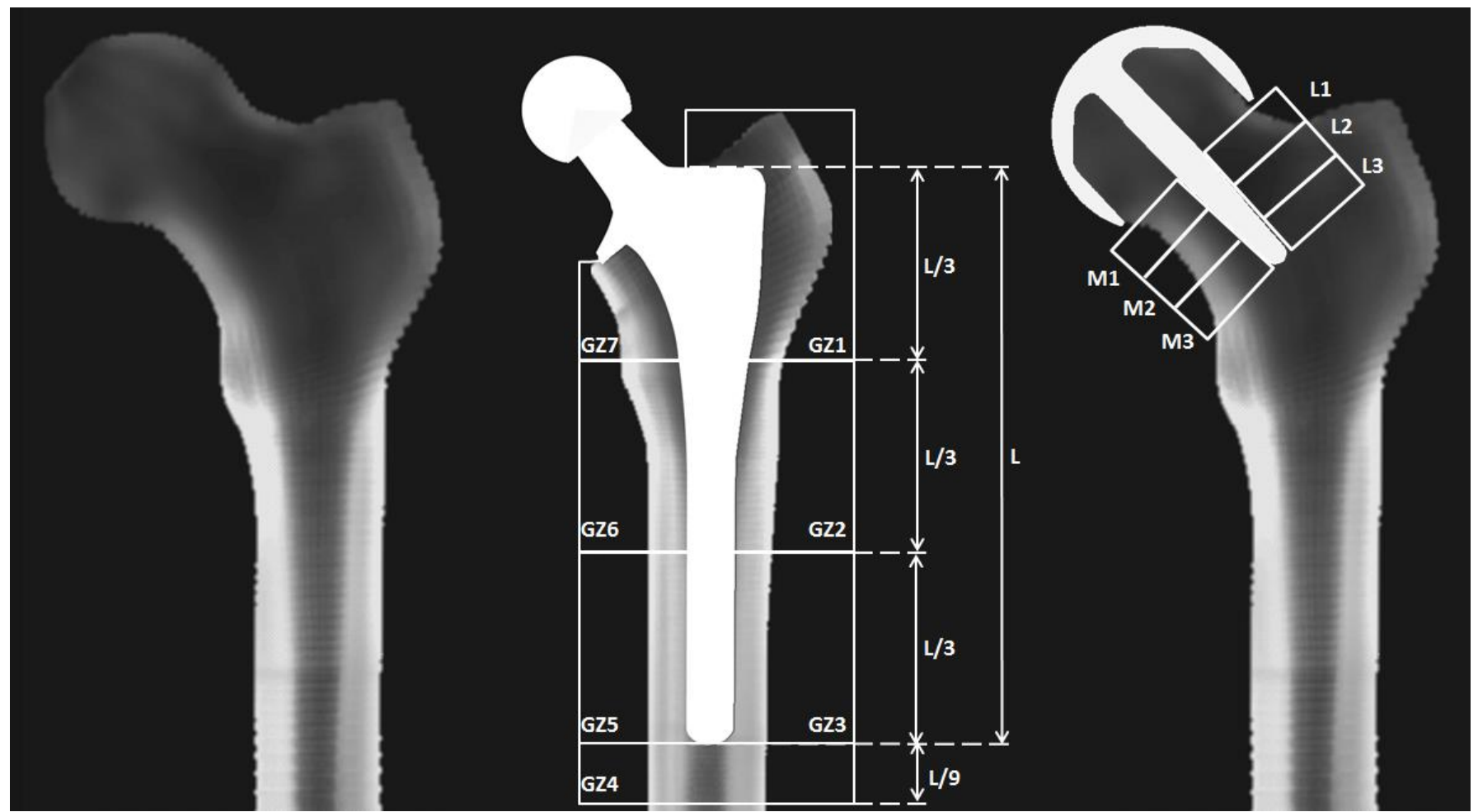

Figure 2: Virtual x-ray of intact bone (left) and zones defined for virtual DXA scan in cementless THR (centre) and RHR models (right) 


\section{Results}

\section{Cementless THR}

Around the cementless THR, the characteristic trends of proximal load bypass were predicted (Figure 3, Table 2): BMD loss in GZs 6 and 7, and a slight BMD increase in GZ4. In the Control case THR1, progressive and unrealistic BMD losses were observed in the lateral-distal GZs 2 and 3, and an early BMD increase was predicted the greater trochanter. Less than $0.1 \%$ BMD change was predicted to occur in GZ6. When the recovery activity and load profiles were incorporated in the modified models, in all zones apart from GZ7 the trends and homeostatic levels of BMD change were different. In GZ6 a faster stabilising BMD loss was predicted. A slight BMD loss-recovery trend was observed in the distal zones, and a more marked BMD loss-increase trend was seen in proximal-lateral GZs 1 and 2.

\begin{tabular}{|l|ccccccc|}
\hline & \multicolumn{7}{|c|}{ Areal BMD at 60 Months, g/cm ${ }^{2}$ (Change in parentheses) } \\
& GZ1 & GZ2 & GZ3 & GZ4 & GZ5 & GZ6 & GZ7 \\
\hline Preoperative & 0.582 & 1.377 & 1.689 & 1.397 & 1.679 & 1.397 & 1.149 \\
\hline THR 1: & 0.586 & 1.319 & 1.657 & 1.418 & 1.687 & 1.396 & 1.013 \\
Control 75\% & $(0.71)$ & $(-4.00)$ & $(-1.73)$ & $(+1.48)$ & $(+0.46)$ & $(-0.09)$ & $(-11.85)$ \\
\hline THR 2: & 0.572 & 1.354 & 1.674 & 1.408 & 1.661 & 1.333 & 1.009 \\
Weak Recovery & $(-1.78)$ & $(-1.68)$ & $(-0.88)$ & $(+0.69)$ & $(-1.07)$ & $(-4.55)$ & $(-12.21)$ \\
\hline $\begin{array}{l}\text { THR 3: } \\
\text { Intermediate Recovery }\end{array}$ & 0.573 & 1.362 & 1.673 & 1.416 & 1.660 & 1.329 & 1.015 \\
\hline THR 4: & $(-1.56)$ & $(-1.15)$ & $(-0.90)$ & $(+1.25)$ & $(-1.14)$ & $(-4.86)$ & $(-11.66)$ \\
Strong Recovery & 0.590 & 1.396 & 1.692 & 1.436 & 1.670 & 1.344 & 1.061 \\
\hline Cemented THR: & $(+1.41)$ & $(+1.30)$ & $(+0.17)$ & $(+2.72)$ & $(-0.56)$ & $(-3.76)$ & $(-7.68)$ \\
Strong Recovery & & & & & & \\
(Dickinson 2014) & $(-2.19)$ & $(-2.88)$ & $(+1.52)$ & $(+4.86)$ & $(+1.54)$ & $(-6.49)$ & $(-12.10)$ \\
\hline $\begin{array}{l}\text { Cemented THR: } \\
\text { (Jayasuriya 2013) }\end{array}$ & & & & & \multirow{2}{*}{$(-5.81)$} & $(-13.00)$ \\
\hline
\end{tabular}

Table 2: BMD changes per Gruen zone for the four Total Hip Replacement simulated cases, predicted after 60 months

These changes were visualised by virtual x-ray (example in Figure 4), including characteristic changes of medial calcar resorption back to the implant collar (A), formation of a cortical layer on the osteotomy surface (B), formation of extending trabecular structures from the cortex to the implant proximally $(C$ and $D)$, lateral trabecular resorption $(E)$ and slight distal pedestal formation (F). All recovery cases produced virtual $\mathrm{x}$-ray results at homeostasis that were qualitatively similar, which supports the virtual DXA scan as a more sensitive, quantitative output measure than $\mathrm{x}$-ray. 

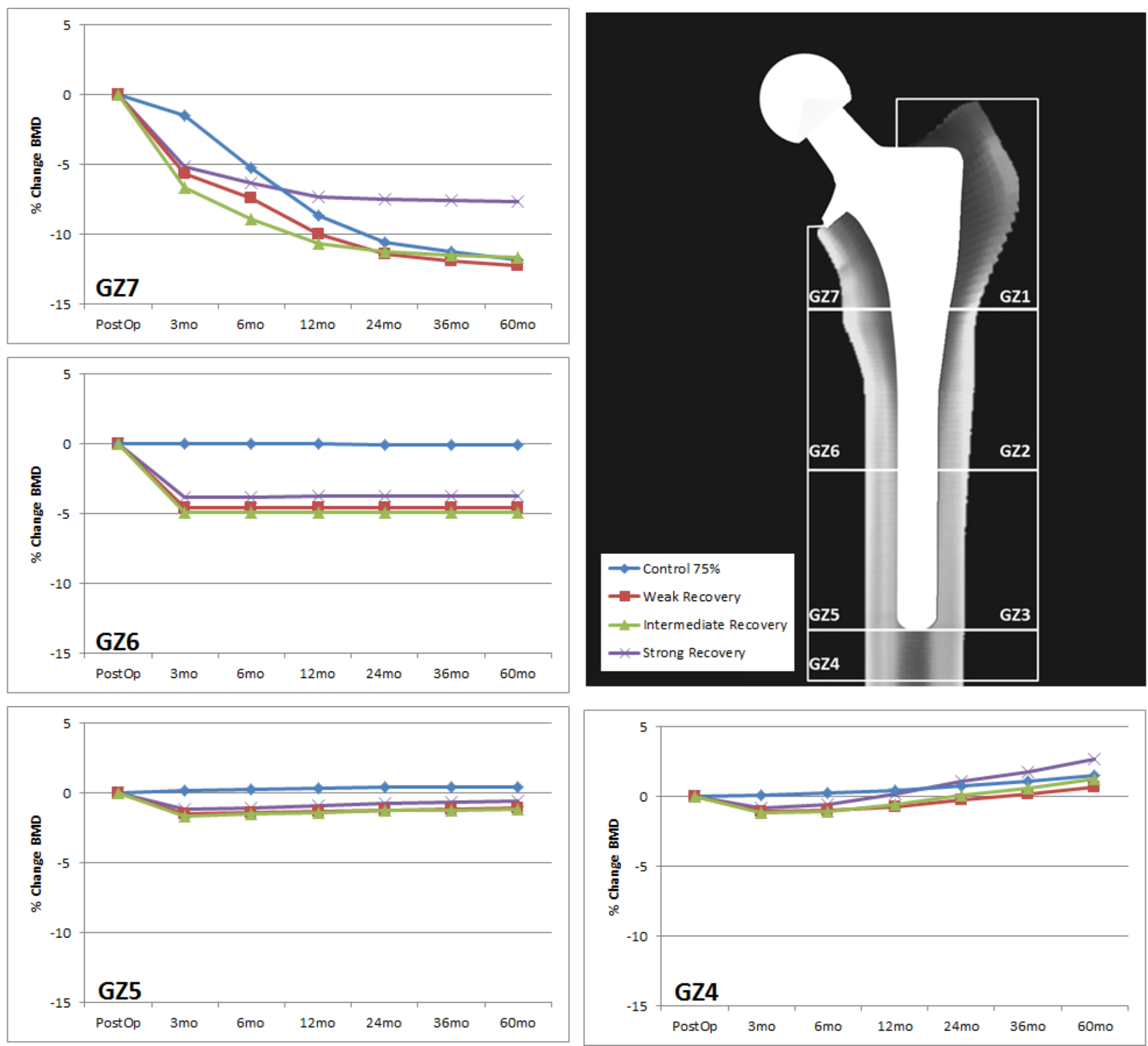

$\rightarrow$-Weak Recovery

$\rightarrow$ Intermediate Recovery

* Strong Recovery
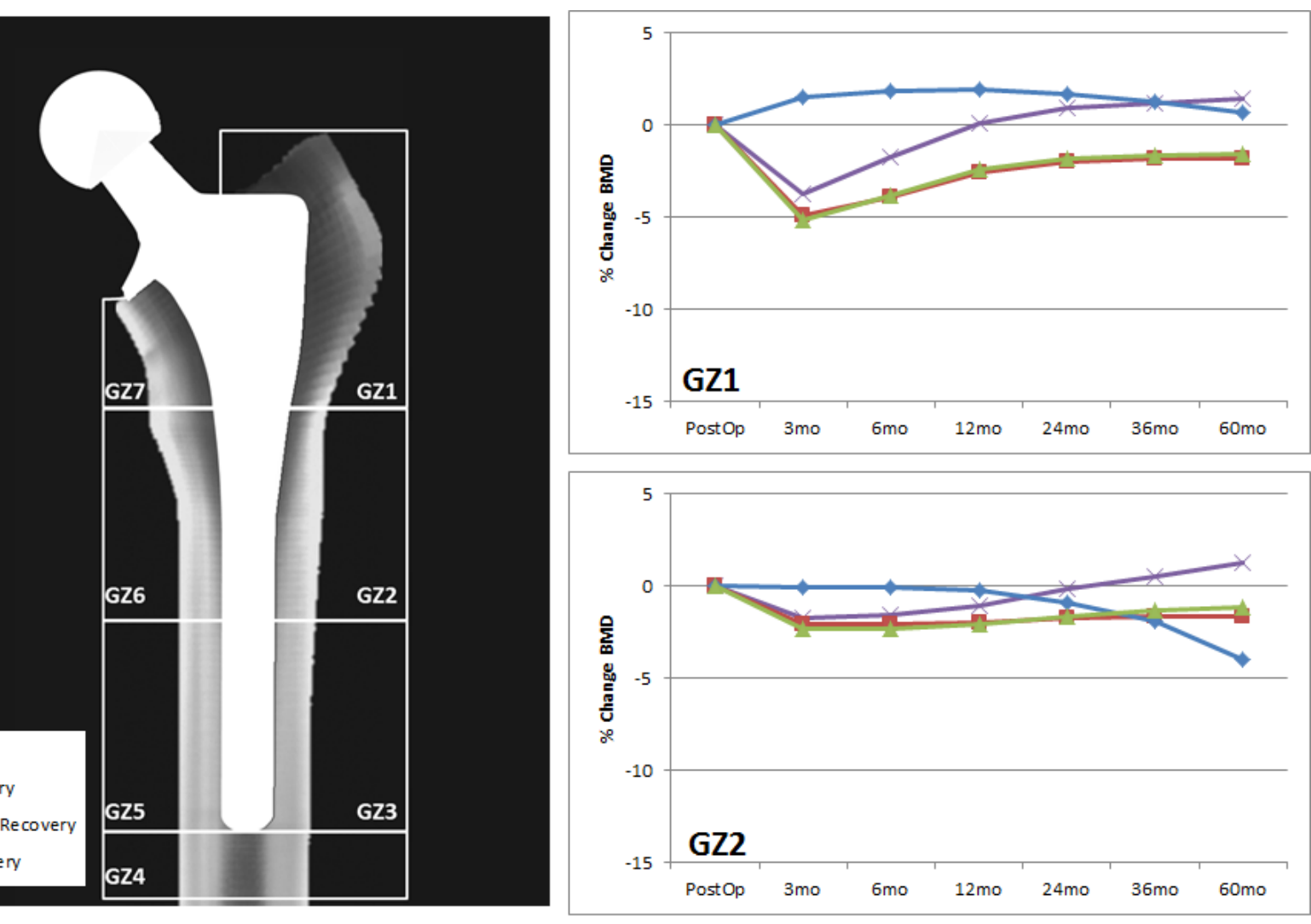

Figure 3: Predicted percentage change in BMD per Gruen zone around the cement

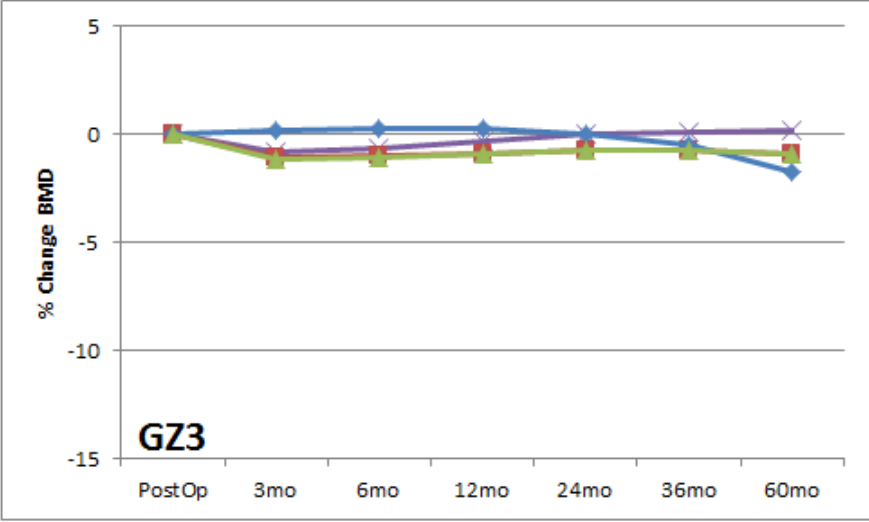

with $75 \%$ threshold remodelling stimulus. 


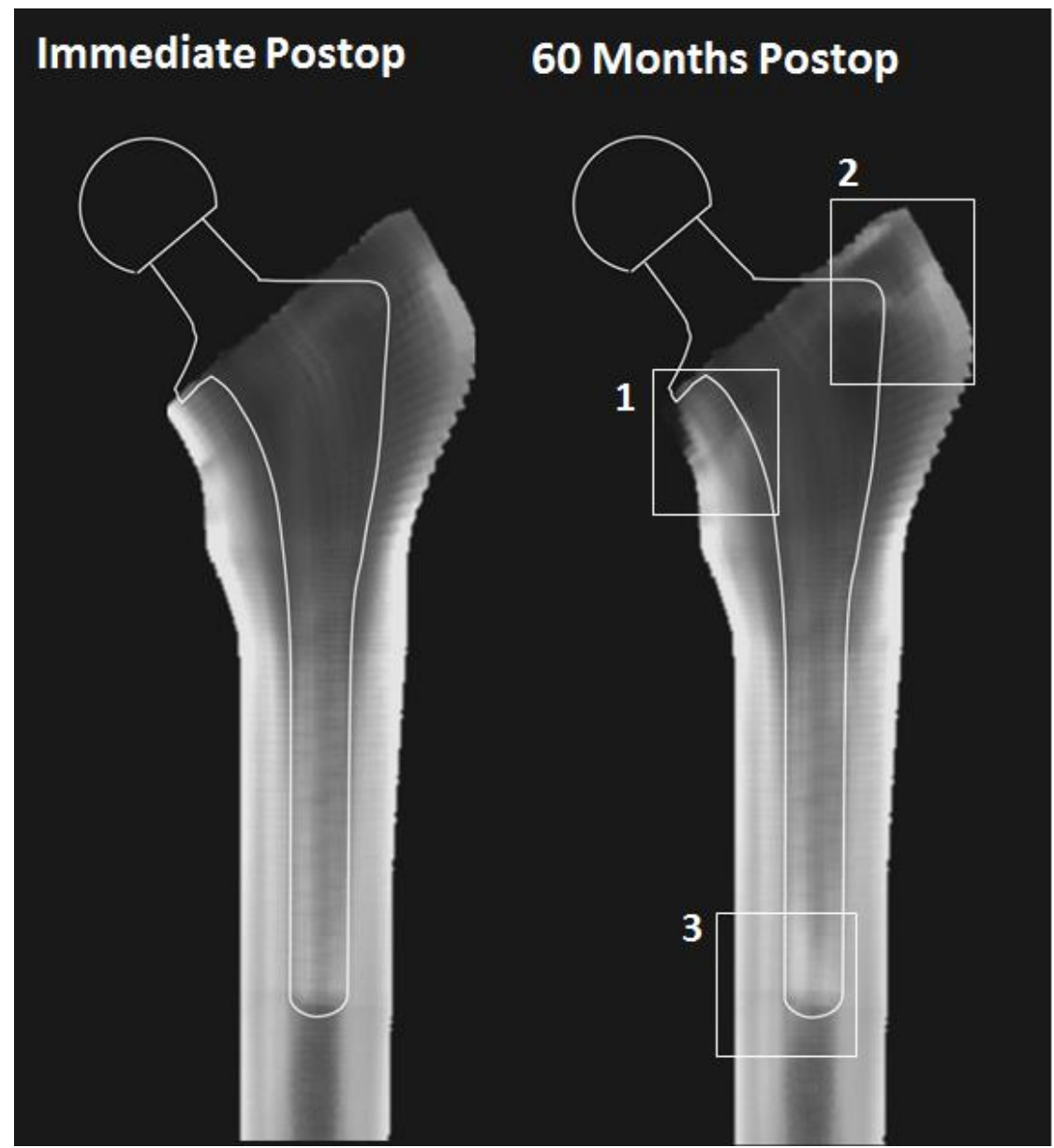

\section{1: Collar / Medial Calcar}
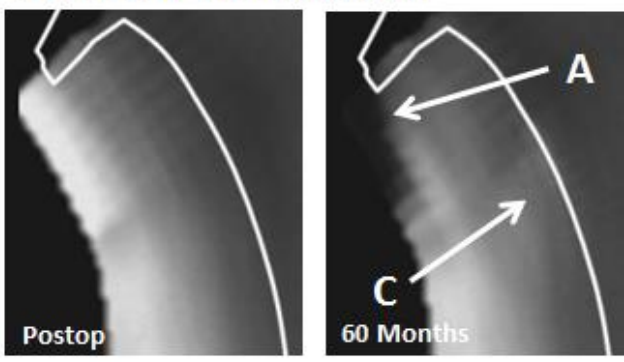

2: Shoulder / Greater Trochanter

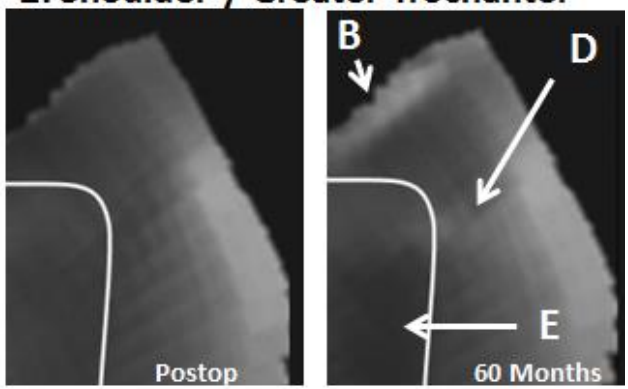

3: Stem Tip / Diaphysis

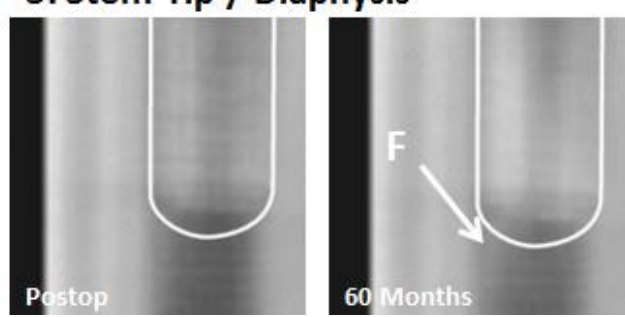

Figure 4: Virtual anterior-posterior x-rays showing changes in BMD around the cementless THR for the intermediate recovery scenario. Notable observations are marked and described in the text.

\section{Hip Resurfacing (RHR)}

Around the RHR, the characteristic trends of medial femoral neck load bypass along the metaphyseal stem were predicted (Figure 5, Table 3) but were slight in the $75 \%$ threshold stimulus control case (RHR1). BMD loss was predicted in zones M1 and L1 at the head-neck junction, which is characteristic of femoral neck narrowing. Into the distal femoral neck, zones M2 and M3, slight densification was observed. BMD increases in zones M3 and L3 were observed, consistent with increased loading at the stem tip. With the lower threshold stimulus of $62.5 \%$ (case RHR2), trends were similar but more pronounced, with changes occurring after an initial density drop during the first three postoperative months. When the recovery activity and load profiles were incorporated in the modified models, the trends and homeostatic levels of BMD change were different. In all zones, a loss-recovery trend was observed, with increases to higher than the preoperative BMD in all zones except M1.

\begin{tabular}{|l|cccccc|}
\hline & \multicolumn{7}{|c|}{ Areal BMD at 24 Months, $\mathbf{g} / \mathbf{c m}^{\mathbf{2}}$ (Change in parentheses) } \\
& L1 & L2 & L3 & M1 & M2 & M3 \\
\hline Preoperative & 1.302 & 1.375 & 2.211 & 2.088 & 2.506 & 3.220 \\
\hline RHR 1: & 1.294 & 1.378 & 2.235 & 2.089 & 2.538 & 3.244 \\
Control 75\% & $(-0.59)$ & $(+0.22)$ & $(+1.11)$ & $(+0.04)$ & $(+1.24)$ & $(+0.74)$ \\
\hline RHR 2: & 1.252 & 1.368 & 2.239 & 2.079 & 2.549 & 3.250 \\
Control 62.5\% & $(-6.96)$ & $(-5.59)$ & $(-2.87)$ & $(-5.57)$ & $(-2.70)$ & $(-1.39)$ \\
\hline RHR 3: & 1.306 & 1.385 & 2.252 & 2.015 & 2.728 & 3.380 \\
Strong Recovery 75\% & $(+0.31)$ & $(+0.73)$ & $(+1.87)$ & $(-3.48)$ & $(+8.83)$ & $(+4.98)$ \\
\hline
\end{tabular}

Table 3: BMD changes per Femoral Neck zone for the three Resurfacing Hip Replacement simulated cases, predicted after 24 months

These changes were visualised by virtual x-ray (Figure 6), although in some cases they are subtle: the recovery case produced characteristic changes of resorption inside the implant shell (A), pedestal formation at the stem tip (B), medial femoral neck densification linking the stem to the medial cortex (C), and slight resorption close to the medial femoral head-neck junction (D), consistent with inferiomedial femoral neck narrowing. 

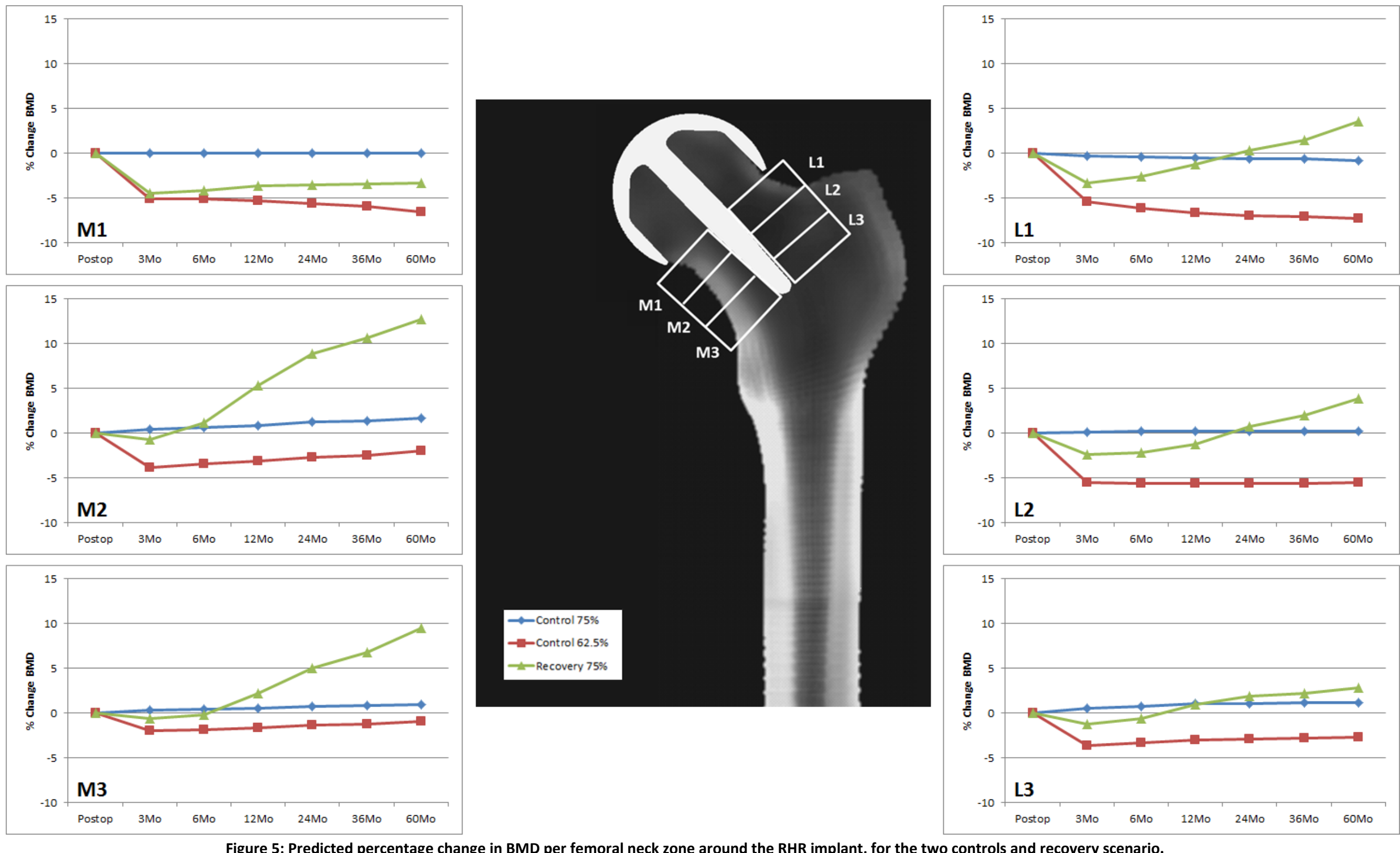

Figure 5: Predicted percentage change in BMD per femoral neck zone around the RHR implant, for the two controls and recovery scenario. 

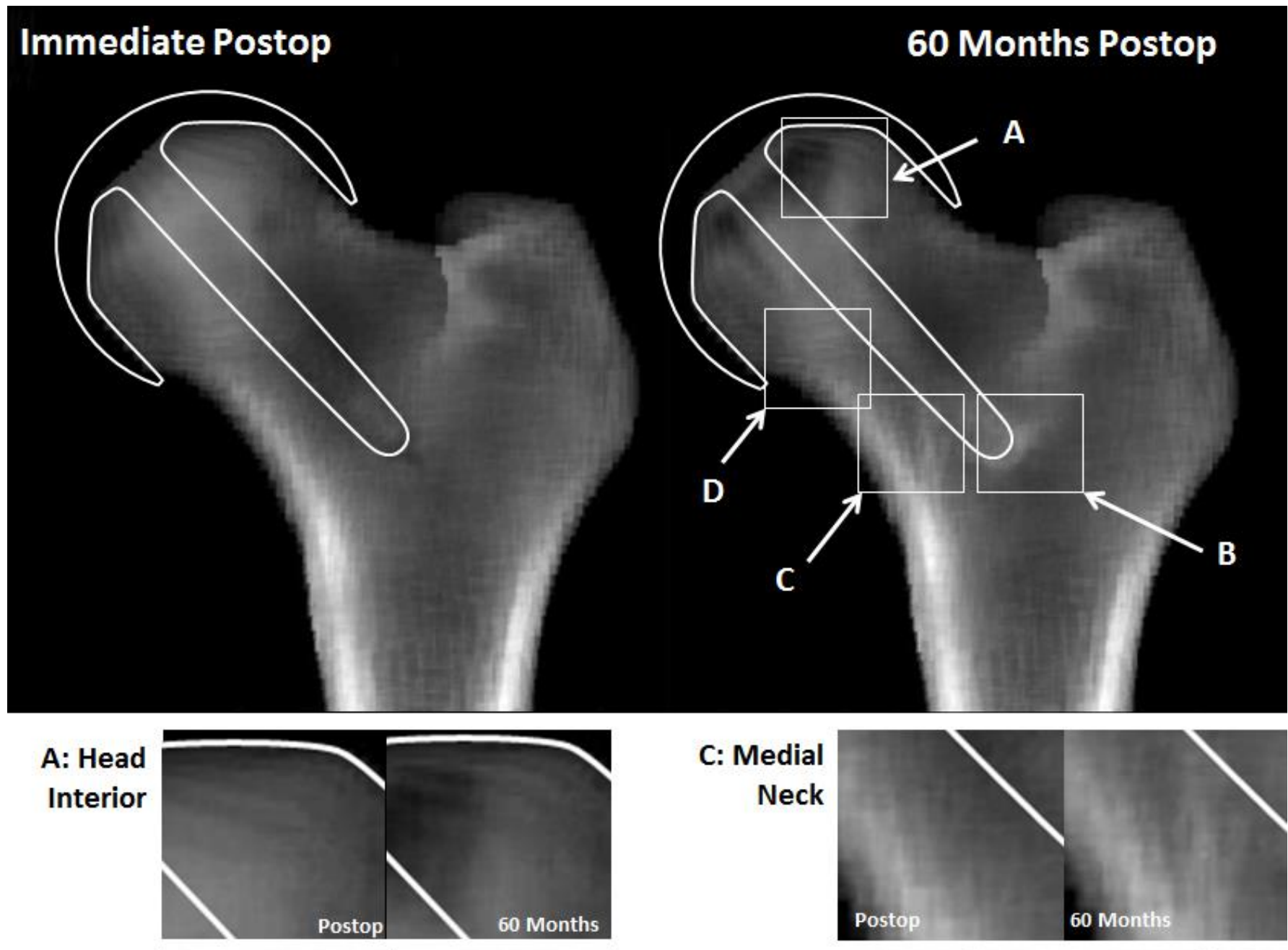

C: Medial
Neck

B: Stem

Tip
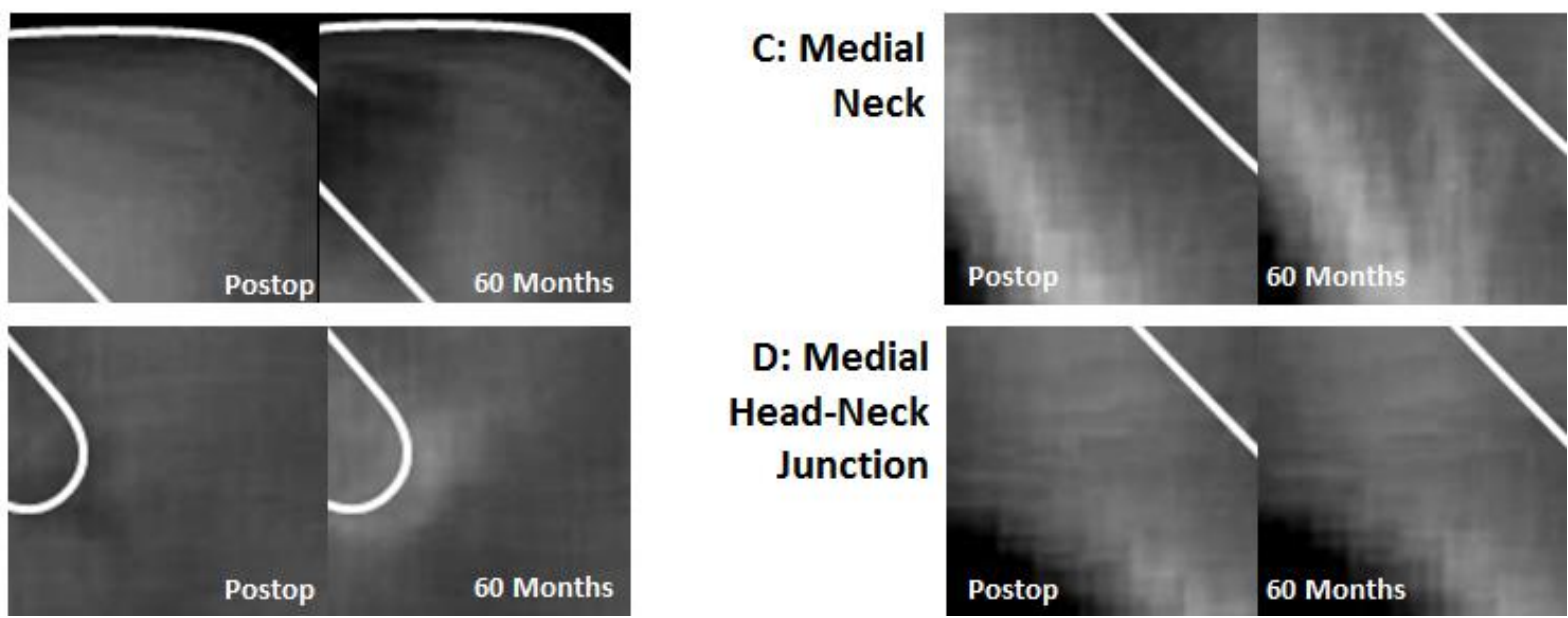

Figure 6: Virtual anterior-posterior x-rays showing changes in BMD around the RHR for the $75 \%$ threshold remodelling stimulus, strong recovery scenario. Notable observations are marked and described in the text. 


\section{Discussion}

This study set out to evaluate the performance of a modification to a traditional computational strain-adaptive bone remodelling prediction method, which accounts for changes in joint loading and patient activity. This approach has been demonstrated to improve the temporal BMD trends and absolute changes predicted to occur around a cemented Charnley THR implant, in particular relating to stress shielded regions, and the present work aimed to evaluate it for a cementless THR and a hip resurfacing implant. The predicted remodelling was compared to clinical data, qualitatively using x-ray evidence and quantitatively where possible using DXA.

Both models demonstrated qualitatively the full set of bone adaptations commonly observed by radiography. Around the Furlong stem, which has demonstrated excellent medium and long term survivorship since 1985, common remodelling signs include osseointegration and extending trabeculae around the tapered proximal portion of the stem, slight calcar resorption, and formation of a trabecular pedestal or 'osteoblastic reaction' at the stem tip (Singh et al 2004; Slack et al 2006; Sandiford et al 2013). Clinical DXA scanning in Furlong and Charnley stems in patients with one of each prosthesis (Chandran et al 2012) demonstrated higher BMD in all Gruen Zones except for 4, reaching significant levels in GZs 2,3,5 and 6. This is consistent with the trends predicted by the models in the present and preceding study (Dickinson 2014) (Table 2, Figure 7), in particular proximally, and the focus of distal hypertrophy predicted by the present Furlong model study can be attributed to the relatively large size implant selected for the selected bone, which fills the canal and thus leaves little space for trabecular densification in GZs 3 and 5.

Considering the BHR implant, which has performed well clinically since its introduction in 1997, characteristic adaptations include narrowing of the femoral neck, medial trabecular densification and formation of pedestal lines around the metaphyseal stem (McMinn et al 1996; Pollard et al 2006; Hing et al 2007; Steffen et al 2008). Further changes observed after retrieval include resorption inside the femoral head. All these changes are characteristic of most comparable hip resurfacing femoral components (Amstutz, Beaulé et al 2004; Spencer et al 2008), and were under-predicted by the model if the established control algorithm was used with the literature standard $75 \%$ threshold remodelling stimulus. More extensive resorption was predicted if a smaller threshold remodelling stimulus of $62.5 \%$ was used, but this is in disagreement with quantitative clinical data which shows a clear loss-recovery trend in the lateral neck and a progressive BMD increase in the medial neck (Lian et al 2008), especially distal to the head-neck junction (Kishida et al 2004; Häkkinen et al 2011; Penny et al 2012; Gerhardt et al 2014). Quantitative comparison of the predicted and clinically measured BMD changes remains difficult with hip resurfacing implants, owing to the variety of DXA zone definitions in these cited studies. DXA measurements are reported to be highly sensitive to the selected zone, and the zone has been shown to influence the achievable precision around THR stems and acetabular cups (Wilkinson et al 2001). However, given the extent of variability reported in literature DXA data within-study, the trends and absolute homeostatic BMD changes predicted using the modified strain adaptive remodelling process were judged to be adequate.

The temporal loss-recovery trend in periprosthetic BMD may be of particular importance where RHR implants are studied. Extensive clinical results and registry data shows that the risk of femoral neck fracture is greatest during the postoperative recovery period. This is thought to be linked to incorrect implant positioning, intraoperative bone damage from osteotomy and impaction loads, and bone cement exotherm, amongst other factors (Amstutz, Campbell et al 2004; Shimmin and Back 2005). In that case it is logical that numerical investigations of this complication should be accounting for the fact that BMD drops postoperatively before recovering, as this would be expected to contribute further to temporarily elevated periprosthetic bone strain and fracture risk. 


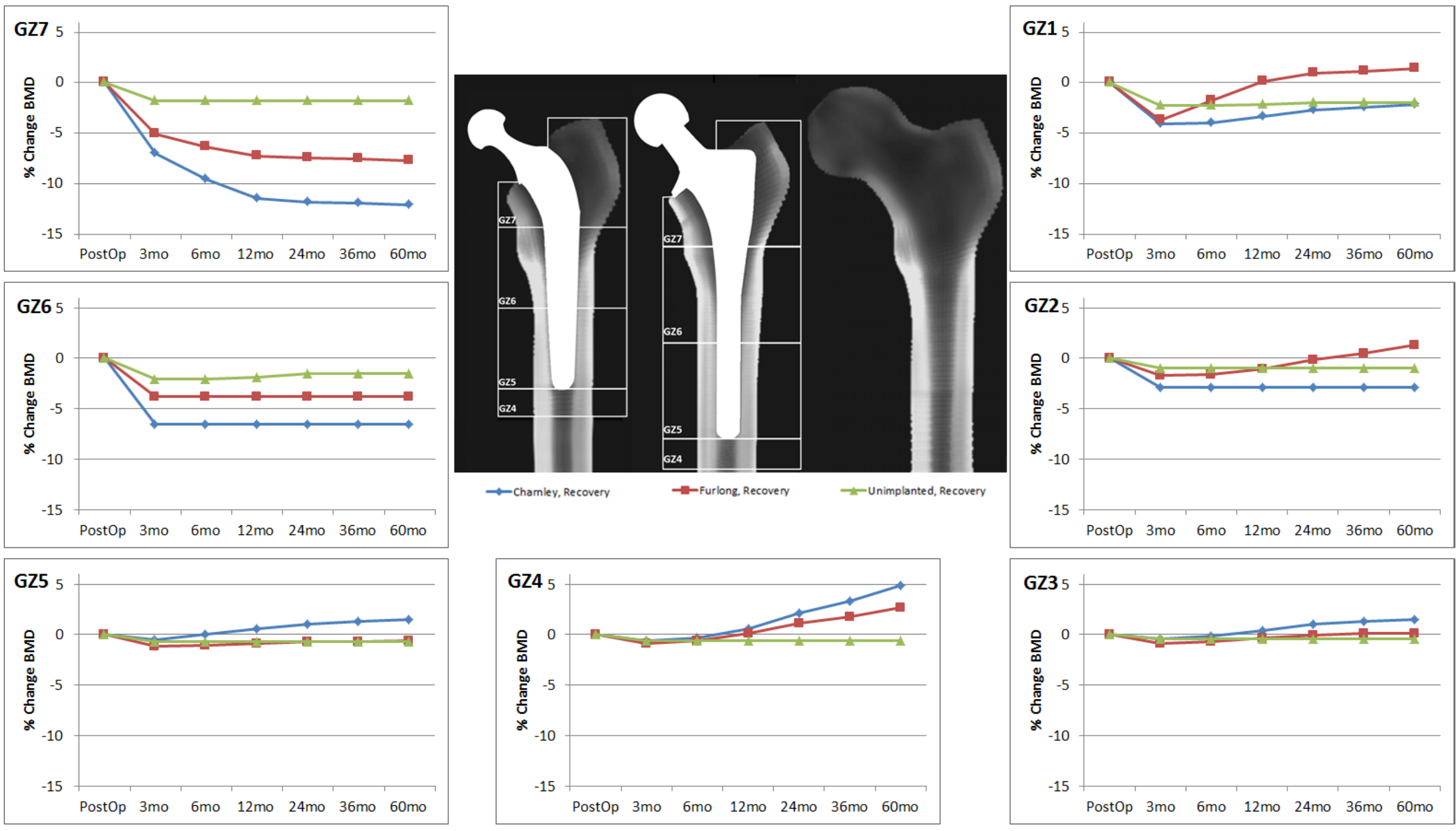

Figure 7: Predicted percentage change in BMD per Gruen zone around the cementless and cemented THR implants from (Dickinson 2014), for the strong recovery activity and load profile scenario, contrasted with the activity and load profile changes applied to an unimplanted femur. Models run at $75 \%$ threshold remodelling stimulus. 
One point of interest was the relative contributions of the applied activity and load profiles and the presence of the implant to the predicted remodelling. Therefore, the remodelling process with a strong recovery load and activity profile (recovery over 12 months to a final $30 \%$ postoperative increase in activity, use of one cane preoperatively and unaided postoperative gait) was applied to an intact femur model, and compared to the predictions for the original Charnley cemented and Furlong cementless THR models (Figure 7). In each Gruen zone, the BMD change associated with the changed activity and loading only was less than $2.5 \%$. This demonstrated that in this simplified model, although the influence of the extrinsic effects have are important, the mechanics of implantation are dominant.

These results are consistent with prior computational work, which evaluated the effect of activity upon remodelling in the intact femoral neck (Machado et al 2013). Other groups have evaluated the agreement between FE predictions and DXA measurements (Herrera et al 2007; Herrera et al 2014; ten Broeke et al 2014), although to obtain a close fit these models require retrospective tuning. This is acknowledged as a limitation of the present study to a degree, although with the exception of the threshold remodelling stimulus, all parameters used in this approach were selected from the surgical and rehabilitation biomechanics literature and are representative of external factors only. Furthermore, the results obtained from direct application of these methods to two further implant types lend confidence to their predictions in application to new prosthesis concepts.

The present approach may be useful to design engineers investigating implant design optimisation. The presented results consider only two designs so the sensitivity to design parameters (e.g. geometry, material, and interface or fixation characteristics) cannot be reliably stated. However, clear differences between the load transfer distribution and net remodelling caused by the Charnley and Furlong designs can be observed (Figure 7), which agree with comparative clinical data (Chandran et al 2012). The polished cemented stem shows greater distal hypertrophy (GZ4) as it is free to slide within the cement mantle and load distally, and the cementless stem shows less proximal stress shielding (GZs 6 and 7), possibly due to its lower stiffness, and proximal hypertrophy (GZs 1 and 2) where implant-bone fixation allows load transfer which is reduced for the polished cemented implant.

One limitation of the present methodology is that this study considers changes in the intensity of activity, rather than more fundamental changes in the activity types undertaken. As a purely comparative study, the study employs the assumption that the pre- and postoperative activity types are unchanged, and considers gait loading alone. Gait has been reported to represent the great majority of daily dynamic activity in THR patients, at $10.2 \%$ ( $\pm 5.3 \%$ S.D.) of total time vs. $0.4 \%$ ( $\pm 0.4 \%$ S.D.) for stair climbing (Morlock et al 2001 ). It can be suggested that the types of activity undertaken may become more varied by the end of the recovery and rehabilitation period. This may include a return to higher magnitude loading sporting activities, particularly in younger individuals with THR and RHR. This effect will be captured indirectly by the present methodology to some extent, if it provides a contribution to the increased activity intensity. Neglect of its explicit inclusion in the methodology would logically make the predictions of postoperative BMD recovery conservative. Also neglected by the present methodology is the longer term reduction in activity intensity associated with increasing age. This highly variable effect is significant but is measured over a longer period than the 5 -year postoperative time simulated (Kinkel et al 2009).

Further limitations to the present study include the use of a single bone model and, for each implant, a single, idealised surgical position and load case. Furthermore, the single load case is represented by a single quasi-static load instant, but it is possible that the peak stimulus is experienced by different locations in the femur under different points of the gait cycle. The study relies on capturing a representative, approximately normal patient, but it is recognised that the greatest clinical challenges come from patients whose anatomy, loading or surgical result differs substantially from normal. At present, the results are compared to mean clinical data, but an 
important future study must investigate the effects of inter-patient and surgical variability. Such a study was precluded in the past by the high computational expense of these iterative FE analyses, but the mapped hexahedral meshed THR models presented are capable of a full remodelling solution of 30-60 iterations in under 36 hours on a desktop computer. Considering realism of input loading, multiple load cases and loading points in gait or other activity cycles could be superimposed (Bitsakos et al 2005). However, this would produce a direct increase in solution time and in this case, use of a single quasi-static load produced an acceptable agreement with clinical data, although this assumption may not be valid for all implant types. Of greater importance might be the consideration of patient specific hip contact and muscle forces, and their pre- to postoperative changes (Jonkers et al 2008). With sufficient input data, multi-patient analysis using this method could be achieved with relatively low computational expense by modifying this verified mesh by freeform deformation (Fernandez et al 2013), and employing mesh morphing to incorporate the effects of surgical variability (Bah et al 2011) and implant sizing.

Furthermore, longer term effects may be incorporated in this technique, such as the previously mentioned agerelated activity changes, and comorbidities such as osteoporotic degeneration. To help the reader to associate the present model's predictions to clinical practice, it is noted that the predicted maximum periprosthetic BMD losses in the three implants simulated was $10-20 \%$, tuned to correspond with mean clinical measurements. More marked changes may result from comorbidities such as osteoporosis, which has been reported to produce a BMD loss in the region of $45-50 \%$ in comparison to osteoarthritic individuals (Sun et al 2008). More varied, and more extreme changes would be observed as a result of osteolytic bone destruction, potentially requiring revision surgery if compromising implant stability (Della Valle and Paprosky 2004). Through incorporation of longer term activity changes, or superimposition of progressive degeneration, the performance of implant design concepts could be predicted for particular patient groups of concern, including the elderly and the osteoporotic. Although other effects may dominate, such as further bone loss during primary implant removal, these techniques could also contribute to predicting the implications of periprosthetic adaptations around primary implants for the performance of revision implants.

The employed methodology is a considerable simplification of the scenario it represents, where the healing and recovery from orthopaedic surgery and the subsequent bone adaptation in response to prostheses involve a highly complex set of mechanobiological processes. In addition to remodelling, the cementless implant scenario involves the healing of surgical damage to the bone and surrounding soft tissues, transient responses to primary implant fixation, potentially external remodelling, and often the progressive osseointegration of implants through bioactive surface coatings for secondary fixation. Osseointegration has been simulated alone and combined with remodelling (Tarala et al 2011), and the effects of progressive implant-cement and implant-bone interface fixation and failure have been considered in hip resurfacing ( $P a l$ et al 2009; Caouette et al 2013). A simplification of the present study is the neglect of these effects. A critical factor in the development of preclinical analysis methods for new medical devices is establishing an appropriate level of modelling complexity. The engineer and expert clinicians must judge what the most sensitive mechanobiological processes in a particular implant system are, and which micro- or macroscopic level predictions are necessary. The predictions of the adaptive bone remodelling process used in this study are not a perfect representation of the clinical scenarios they represent, and work continues to establish accurate and efficient mechanobiological models in response to native physiology and bioactive implant technology (Tarala et al 2013; ten Broeke et al 2014). This study supports the application of predictive bone remodelling as one element in the range of computational and physical tests which should be conducted in the pre-clinical evaluation of new prostheses. 


\section{Acknowledgements}

Funding: this study was funded by the New Frontiers Fellowship scheme at the University of Southampton's Faculty of Engineering and the Environment.

Geometry of the Furlong implant was provided by Prof E Draper of JRI Ltd, Sheffield, UK.

\section{Conflicts of Interest}

The author has performed paid consultancy for JRI Ltd on unrelated work to that presented in this paper.

\section{References}

Abadie, P., Lebel, B, Pineau, V, Burdin, G, Vielpeau, C (2010). "Cemented Total Hip Stem Design Influence on Adaptive Cortical Thickness and Femoral Morphology." Orth \& Traum: Surg \& Res 96: 104-110.

Adachi, T., Tomita, Y, Sakaue, H, Tanaka, M (1997). "Simulation of trabecular surface remodeling based on local stress nonuniformity." JSME Int J Ser C 40(4): 782-792.

Ajemian, S., Thorn, D, Clare, P, Kaul, L, Zernicke, R F, Loitz-Ramage, B (2004). "Cane-Assisted Gait Biomechanics and Electromyography after Total Hip Arthroplasty." Arch Phys Med Rehabil 85: 1966-1971.

Amstutz, H. C., Beaulé, P E, Dorey, F J, Le Duff, M J, Campbell, P A, Gruen, T A (2004). "Metal-on-metal hybrid surface arthroplasty: two to six-year follow-up study." J Bone Joint Surg [Am] 86: 28-39.

Amstutz, H. C., Campbell, P A, Le Duff, M J (2004). "Fracture of the neck of the femur after surface arthroplasty of the hip." J Bone Joint Surg [Am] 86: 1874-1877.

Bah, M. T., Nair, P B, Taylor, M, Browne, M (2011). "Efficient Computational Method for Assessing the Effects of Implant Positioning in Cementless Total Hip Replacements." J Biomech 44: 1417-1422.

Bitsakos, C., Kerner, J, Fisher, I, Amis, A (2005). "The effect of muscle loading on the simulation of bone remodelling in the proximal femur." J Biomech 38: 133-139.

Bobyn, J. D., Mortimer, E S, Glassman, A H, Engh, C A, Miller, J E, Brooks, C E (1992). "Producing and avoiding stress shielding: laboratory and clinical observations of noncemented total hip arthroplasty." Clin Ortho Rel Res 274: 79-96.

Bonnin, M. P., Archbold, P H A, Basiglini, L, Fessy, M H, Beverland, D E (2012). "Do we Medialise the Hip Centre of Rotation in Total Hip Arthroplasty? Influence of Acetabular Offset and Surgical Technique." Hip International 22: 371-378.

Boyle, C., Yong Kim, I (2011). "Comparison of Different Hip Prosthesis Shapes considering Micro-Level Bone Remodeling and StressShielding Criteria using Three-Dimensional Design Space Topology Optimization." J Biomech 44: 1722-1728.

Brand, R. A., Crowninshield, R D (1980). "The Effect of Cane Use on Hip contact Force." Clin Orth 147: 181-184.

Brodner, W., Bitzan, P, Lomoschitz, F, Krepler, P, Jankovsky, R, Lehr, S, Kainberger, F, Gottsauner-Wolf, F (2004). "Changes in bone mineral density in the proximal femur after cementless total hip arthroplasty." J Bone Joint Surg [Br] 86-B: 20-26.

Caouette, C., Bureau, M N, Lavigne, M, Venditolli, P-A, Nuno, N (2013). "A new interface element with progressive damage and osseointegration for modeling of interfaces in hip resurfacing." Proc IMechE Part H: J Eng Med 227: 209-220.

Caouette, C., Bureau, M N, Venditolli, P-A, Lavigne, M, Nuno, N (2012). "Anisotropic bone remodeling of a biomimetic metal-on-metal hip resurfacing implant." Med Eng and Physics 34: 559-565.

Carter, D. R. (1984). "Mechanical Loading Histories and Cortical Bone Remodelling." Calcif Tissue Int 36: S19-S24.

Chandran, P., Azzabi, M, Andrews, M, Bradley, J G (2012). "Periprosthetic Bone Remodeling after 12 Years Differs in Cemented and Uncemented Hip Arthroplasties." Clin Orth Rel Res 470: 1431-1435.

Claes, L. E., Heigele, C A (1999). "Magnitudes of Local Stress and Strain Along Bony Surfaces Predict the Course and Type of Fracture Healing." J Biomech 32: 255-266.

Cohen, B., Rushton, N (1995). "Bone Remodelling in the Proximal Femur after Charnley Total Hip Arthroplasty." J Bone Joint Surg [Br] 77-B: 815-819.

Daniel, J. T., Kamali, A, Li, C, Hussain, A, Pamu, J, Counsell, L, Zaiee, H, McMinn, DWJ (2009). "Step Activity Monitoring of Birmingham Hip Resurfacing Patients at Different Stages following Operation." Trans ORS 55: 366.

de Groot, I. B., Bussmann, H J, Stam, H J, Verhaar, J A (2008). "Small Increase of Actual Physical Activity 6 Months after Total Hip or Knee Arthroplasty." Clin Orth Rel Res 466: 2201-2208.

Della Valle, C. J., Paprosky, W G (2004). "The femur in revision total hip arthroplasty: evaluation and classification." Clin Orthop Rel Res 420: 55-62.

Dickinson, A. S. (2010). Development of Computational Biomechanical Tools to Assess the Performance of the Resurfaced Hip Joint. PhD Thesis. Bioengineering Science Research Group. Southampton, University of Southampton.

Dickinson, A. S. (2014). "Activity and Loading Influence the Predicted Bone Remodeling around Cemented Hip Replacements." Journal of Biomechanical Engineering 136(4).

Dickinson, A. S., Taylor, A C, Browne, M (2012). "Implant-Bone Interface Healing and Adaptation in Resurfacing Hip Replacement." CMBBE 15: 935-947.

Doblaré, M., Garcia, J M (2001). "Application of an anisotropic bone-remodelling model based on a damage-repair theory to the analysis of the proximal femur before and after total hip replacement." J Biomech 34: 1157-1170.

Fernandez, J., Sartori, M, Lloyd, D, Munro, J, Shim, V (2013). "Bone remodelling in the natural acetabulum is influenced by muscle forceinduced bone stress." Int J Numer Meth Biomed Engng Online.

Garcia, J. M., Martinez, M A, Doblaré, M (2001). "An anisotropic internal-external bone adaptation model based on a combination of CAO and continuum damage mechanics technologies." Comp Meth Biomech Biomed Eng 4: 355-377. 
Gerhardt, D. M. J. M., Smolders, J M H, Rijnders, T A J M, Hol, A, van Susante, J L C (2014). "Changes in bone mineral density and femoral neck narrowing in the proximal femur three to five years after hip resurfacing fersus conventional total hip arthroplasty." $\underline{\mathrm{J} \text { Arthoplasty }}$ IN PRESS.

Ghosh, R., Mukherjee, K, Gupta, S (2013). "Bone remodelling around uncemented metallic and ceramic acetabular components." Proc IMechE Part H: J Eng Med 227: 490-502.

Gruen, T. A., McNeice, G M, Amstutz, H C (1979). "'Modes of Failure" of Cemented Stem-Type Femoral Components." Clin Orth Rel Res 141: 17-27.

Gupta, S., New, A M R, Taylor, M (2006). "Bone remodelling inside a cemented resurfaced femoral head." Clin Biomechanics 21: 594-602.

Häkkinen, A., Borg, H, Hauklinen, M, Jurvelin, J, Anttila, E, Parvaiainen, T, Kiviranta, I (2011). "Bone mineral density of the proximal femur after hip resurfacing arthroplasty: 1-year follow-up study." BMC Musculoskeletal Disorders 12: 100.

Heller, M. O., Bergmann, G, Kassi, J-P, Claes, L, Haas, N P, and Duda, G N (2005). "Determination of muscle loading at the hip joint for use in pre-clinical testing." J Biomech 38: 1155-1163.

Herrera, A., Panisello, J J, Ibarz, E, Cegonino, J, Puertolas, J A, Gracia, L (2007). "Long-term study of bone remodelling after femoral stem: A comparison between dexa and finite element simulation." J Biomech 40: 3615-3625.

Herrera, A., Rebollo, S, Ibarz, E, Mateo, J, Gabarre, S, Gracia, L (2014). "Mid-Term Study of Bone Remodeling after Femoral Cemented Stem Implantation: Comparison between DXA and Finite Element Simulation." J Arthroplasty 29: 90-100.

Hing, C. B., Young, D A, Dalziel, R E, Bailey, M, Back, D L, Shimmin, A J (2007). "Narrowing of the neck in resurfacing arthroplasty of the hip." J Bone Joint Surg [Br] 89-B: 1019-1024.

Huang, Q., Shen, B, Yang, J, Zhou, Z, Kang, P, Pei, F (2013). "Changes in bone mineral density of the acetabulum and proximal femur after totla hip resurfacing arthroplasty." J Arthoplasty 28: 1811-1815.

Huiskes, R., Weinans, H, Grootenboer, H J, Dalstra, M, Fudala, B, Slooff, T J (1987). "Adaptive bone remodelling theory applied to prosthetic design analysis." J Biomech 20: 1135-1150.

Jang, I. G., Kim, I Y (2010). "Computational Simulation of Simultaneous Cortical and Trabecular Bone Change in Human Proximal Femur during Bone Remodeling." J Biomech 43: 294-301.

Jayasuriya, R. L., Buckley, S C, Hamer, A J, Kerry, R M, Stockley, I, Tomouk, M W, Wilkinson, J M (2013). "Effect of Sliding-Taper compared with Composite-Beam Cemented Femoral Prosthesis Loading Regime on Proximal Femoral Bone Remodeling." J Bone Joint Surg [Am] 95: 19-27.

Johnston, R., Brand, RA, Crowninshield, RD (1979). "Reconstruction of the Hip: A Mathematical Approach to Determine Optimum Geometric Relationships." J Bone Joint Surg [Am] 61: 639-652.

Jonkers, I., Sauwen, N, Lenaerts, G, Mulier, M, Van der Perre, G, Jaecques, S (2008). "Relation between subject-specific hip joint loading, stress distribution in the proximal femur and bone mineral density changes after total hip replacement." J Biomech 41: 3405-3413.

Kerner, J., Huiskes, R, van Lenthe, G H, Weinans, H, van Rietbergen, B, Engh, C A, Amis, A A (1999). "Correlation between pre-operative and post-operative bone loss in THA can be explained by strain-adaptive remodelling." J Biomech 32: 695-703.

Kim, Y.-H., Yoon, S-H, Kim, J-S (2007). "Changes in the Bone Mineral Density in the Acetabulum and Proximal Femur after Cementless Total Hip Replacement." J Bone Joint Surg [Br] 89-B: 174-179.

Kinkel, S., Wollmerstedt, N, Kleinhaus, J A, Hendrich, C, Heisel, C (2009). "Patient activity after total hip arthroplasty declines with advancing age." Clin Orthop Rel Res 467: 2053-2058.

Kishida, Y., Sugano, N, Nishii, T, Miki, H, Yamaguchi, K, Yoshikawa, H (2004). "Preservation of the bone mineral density of the femur after surface replacement of the hip." J Bone Joint Surg [Br] 86-B: 185-189.

Kuhn, M., Harris-Hayes, M, Steger-May, K, Pashos, G, Clohisy, J C (2013). "Total Hip Arthroplasty in Patients 50 Years of Less. Do we Improve Activity Profiles?" J Arthoplasty 28: 872-876.

Leichtle, U. G., Leichtle, C I, Schmidt, B, Martini, F (2005). "Peri-prosthetic bone density after implantation of a custom-made femoral component." J Bone Joint Surg [Br] 88-B: 467-471.

Lian, Y., Pei, F, Yoo, M, Cheng, J, Fatou, C (2008). "Changes of Bone Mineral Density in Proximal Femur following Total Hip Resurfacing Arthroplasty in Osteonecrosis of Femoral Head." J Orth Res 26: 453-459.

Machado, M. M., Fernandes, P R, Cardadeiro, G, Baptista, F (2013). "Femoral neck bone adaptation to weight-bearing physical activity by computational analysis." J Biomech 46: 2179-2185.

Martin, R. B. (1984). "Porosity and Specific Surface of Bone." CRC Crit Rev Biomed Eng 10: 179-222.

McMinn, D., Treacy, R, Lyn, K, Pynsent, P (1996). "Metal-on-metal surface replacement of the hip." Clin Ortho Rel Res 329S: S89-S98.

Morgan, E. F., Bayraktar, H H, Keaveny, T M (2003). "Trabecular Bone Modulus-Density Relationships Depend on Anatomic Site." J Biomech 36: 897-904.

Morlock, M. M., Schneider, E, Bluhm, A, Vollmer, M, Bergmann, G, Muller, V, Honl, M (2001). "Duration and Frequency of Every Day Activities in Total Hip Patients." J Biomech 34: 873-881.

Pal, B., Gupta, S, New, A M (2009). "A Numerical Study of Failure Mechanisms in the Cemented Resurfaced Femur: Effects of Interface Characteristics and Bone Remodelling." Proc IMechE Part H: J Eng Med 223: 471-484.

Penny, J. O., Brixen, K, Varmarken, J E, Ovesen, O, Overgaard, S (2012). "Changes in Bone Mineral Density of the Acetabulum, Femoral Neck and Femoral Shaft, after Hip Resurfacing and Total Hip Replacement." J Bone Joint Surg [Br] 94-B: 1036-1044.

Perez, M. A., Venditolli, P -A, Lavigne, M, Nuno, N (2014). "Bone remodeling in the resurfaced femoral head: effect of cement mantle thickness and interface characteristics." Med Eng and Physics 36: 185-195.

Pollard, T. C. B., Baker, R P, Eastaugh-Waring, S J, Bannister, G C (2006). "Treatment of the Young Active Patient with Osteoarthritis of the Hip: A Five- to Seven-Year Comparison of Hybrid Total Hip Arthroplasty and Metal-on-Metal Resurfacing." J Bone Joint Surg [Br] 88-B: $592-600$.

Rancourt, D., Shirazi-Adl, A, Drouin, G, Paiement, G (1990). "Friction Properties of the Interface between Porous-Surfaced Metals and Tibial Cancellous Bone." J Biomed Mater Res 24: 1503-1519.

Rothstock, S., Uhlenbrock, A, Bishop, N, Laird, L, Nassutt, R, Morlock, M (2011). "Influence of interface condition and implant design on bone remodelling and failure risk for the resurfaced femoral head." J Biomech 44: 1646-1653. 
Sandiford, N., Doctor, C, Rajaratnam, S S, Ahmed, S, East, D J, Miles, K, Butler-Manuel, A, Shepperd, J A N (2013). "Primary total hip replacement with a Furlong fully hydroxyapatite-coated titanium alloy femoral component, results at a minimum follow-up of 20 years." Bone Joint J 95-B: 467-471.

Scannell, P. T., Prendergast, P J (2009). "Cortical and Interfacial Bone Changes around a Non-Cemented Hip Implant: Simulations using a Combined Strain/Damage Algorithm." Med Eng and Physics 31: 477-488.

Shimmin, A. J., Back, D (2005). "Femoral Neck Fractures Following Birmingham Hip Resurfacing: A National Review of 50 Cases." J Bone Joint Surg [Br] 87-B: 463-464.

Singh, S., Trikha, S P, Edge, A J (2004). "Hydroxyapatite ceramic-coated femoral stems in young patients, a prospective ten-year study." J Bone Joint Surg [Br] 86-B: 1118-1123.

Skinner, H. B., Kilgus, D J, Keyak, J, Shimaoka, E E, Kim, A S, Tipton, J S (1994). "Correlation of computed finite element stresses to bone density after remodelling around cementless femoral implants." Clin Orth Rel Res 305: 178-189.

Slack, R., Tindall, A, Shetty, A A, James, K D, Rand, C (2006). "15-year follow-up results of the hydroxyapatite ceramic-coated femoral stem." J Orth Surg 14(2): 151-154.

Spencer, S., Carter, R, Murray, H, Meek, R M D (2008). "Femoral Neck Narrowing After Metal-on-Metal Hip Resurfacing." J Arthroplasty 23: 1105-1109.

Steffen, R. T., Pandit, H P, Palan, J, Beard, D J, Gundle, R, McLardy-Smith, P, Murray, D W, Gill, H S (2008). "The five-year results of the Birmingham Hip Resurfacing Arthroplasty." J Bone Joint Surg [Br] 90-B: 436-441.

Stucinskas, J., Clauss, M, Tarasevicius, S, Wingstrand, H, Ilchmann, T (2012). "Long-Term Femoral Bone Remodelling after Cemented Hip Arthroplasty with the Muller Straight Stem in the Operated and Nonoperated Femora." J Arthroplasty 27: 927-933.

Stulberg, B. N., Fitts, S M, Bowen, A R, Zadzilka, J D (2010). "Early Return to Function after Hip Resurfacing: Is it Better than Contemporary Total Hip Arthroplasty." J Arthoplasty 25: 748-753.

Sun, S.-S., Ma, H-L, Liu, C-L, Huang, C-H, Cheng, C-K, Wei, H-W (2008). "Difference in femoral head and neck material properties between osteoarthritis and osteoporosis." Clin Biomech 23: S39-S47.

Tarala, M., Janssen, D, Verdonschot, N (2011). "Balancing Incompatible Endoprosthetic Design Goals: a Combined Ingrowth and Bone Remodeling Simulation." Med Eng and Physics 33: 374-380.

Tarala, M., Janssen, D, Verdonschot, N (2013). "Toward a method to simulate the process of bone ingrowth in cementless THA using finite element method." Med Eng and Physics 35: 543-548.

ten Broeke, R. H. M., Tarala, M, Arts, J J, Janssen, D W, Vedonschot, N, Geesink, R G T (2014). "Improving peri-prosthetic bone adaptation around cementless hip stems: a clinican and finite element study." Med Eng and Physics 36: 345-353.

Turner, A. W. L., Gillies, R M, Sekel, R, Morris, P, Bruce, W, Walsh, W R (2005). "Computational Bone Remodelling Simulations and Comparisons with DEXA Results." J Orth Res 23: 705-712.

van Lenthe, G. H., de Waal Malefijt, M C, Huiskes, R (1997). "Stress Shielding after Total Knee Replacement may Cause Bone Resorption in the Distal Femur." J Bone Joint Surg [Br] 79-B: 117-122.

van Rietbergen, B., Huiskes, R, Weinans, H, Sumner, D R, Turner, T M, Galante, J O (1993). "The Mechanism of Bone Remodelling and Resorption around Press-Fitted THA Stems." J Biomech 26(369-382).

Weinans, H., Huiskes, R, van Rietbergen, B, Sumner, D R, Turner, T M, Galante, J O (1993). "Adaptive Bone Remodelling around a Bonded Noncemented Total Hip Arthroplasty: a Comparison between Animal Experiments and Computer Simulation." J Orth Res 11: 500-513.

Weinans, H., Huiskes, R, Verdonschot, N, van Rietbergen, B (1991). The Effect of Adaptive Bone Remodelling Threshold Levels on Resorption around Noncemented Hip Stems. Advances in Bioengineering. R. Vanderby. New York, ASME. 20: 303-306.

Wilkinson, J. M., Peel, N F A, Elson, R A, Stockley, I, Eastell, R (2001). "Measuring Bone Mineral Density of the Pelvis and Proximal Femur after Total Hip Arthroplasty." J Bone Joint Surg [Br] 83-B: 238-288.

Wolff, J. (1892). Das Gesetz der Transformation Der Knochen. Berlin. 